\title{
Photocatalytic Activity of Nanostructured Anatase Coatings Obtained by Cold Gas Spray
}

M. Gardon, C. Fernández-Rodríguez, D. Garzón Sousa, J.M. Doña-Rodríguez, S. Dosta, I.G. Cano, and J.M. Guilemany

(Submitted October 31, 2013; in revised form February 19, 2014)

\begin{abstract}
This article describes a photocatalytic nanostructured anatase coating deposited by cold gas spray (CGS) supported on titanium sub-oxide $\left(\mathrm{TiO}_{2-x}\right.$ ) coatings obtained by atmospheric plasma spray (APS) onto stainless steel cylinders. The photocatalytic coating was homogeneous and preserved the composition and nanostructure of the starting powder. The inner titanium sub-oxide coating favored the deposition of anatase particles in the solid state. Agglomerated nano- $\mathrm{TiO}_{2}$ particles fragmented when impacting onto the hard surface of the APS $\mathrm{TiO}_{2-x}$ bond coat. The rough surface provided by APS provided an ideal scenario for entrapping the nanostructured particles, which may be adhered onto the bond coat due to chemical bonding; a possible bonding mechanism is described. Photocatalytic experiments showed that CGS nano- $\mathrm{TiO}_{2}$ coating was active for photodegrading phenol and formic acid under aqueous conditions. The results were similar to the performance obtained by competitor technologies and materials such as dip-coating $\mathbf{P 2 5}{ }^{\circledR}$ photocatalysts. Disparity in the final performance of the photoactive materials may have been caused by differences in grain size and the crystalline composition of titanium dioxide.
\end{abstract}

Keywords cold gas spray, nanostructured $\mathrm{TiO}_{2}$ powder, photocatalysis, wastewater

\section{Introduction}

Reduction of pollutants in the environment has drawn attention on a global framework of different disciplines of research. Development of materials and technologies capable of assuring non-harmful surroundings is challenging a wide range of professionals in the scientific and industrial worlds. Photocatalysis has become an important tool to achieve acceptable levels of depollution. Besides, this process has some advantages toward its competitors: it does not need oxidation agents, and heat is not required for its operation, which reduces the cost of the technology. Nanostructured $\mathrm{TiO}_{2}$-anatase coatings are being applied as functional material in this field due to its high photoactivity, chemical stability, relatively low cost, and large active surface (Ref 1$)$.

Furthermore, the global market for nanotechnology products was estimated at about $\$ 15.7$ billion in 2010 , with an approximate average compound annual growth rate of

M. Gardon, S. Dosta, I.G. Cano, and J.M. Guilemany, Thermal Spray Centre, CPT, University of Barcelona, Martí i Franquès, 1, 08028 Barcelona, Spain; and C. Fernández-Rodríguez, D. Garzón Sousa, and J.M. Doña-Rodríguez, Grupo de Fotocatálisis y Espectroscopía Aplicada al Medioambiente-FEAM (Unidad Asociada al ICMSE-C.S.I.C.), CIDIA-Dpto. de Química, Parque Científico-Tecnológico, Universidad de Las Palmas de Gran Canaria, Campus Universitario de Tafira, 35017 Las Palmas, Spain. Contact e-mail: mgardon@cptub.eu.
$11.1 \%$, which included well-established commercial applications in nanomaterials such as the one presented in this study (Ref 2). Together with the increase in contamination of air and water, industrial and domestic claims may call for large surfaces to be covered by these compounds; for example, by coating processes that can provide balanced performance among cost, yield capacity, operation times, and a satisfactory behavior of the final product.

Adequate efficiencies in heterogeneous photocatalysis are commonly reached by means of applying the active material as a coating. Nonetheless, coating large surfaces with nanostructured $\mathrm{TiO}_{2}$ is not trouble free. Dip-coating processes are commonly used for depositing coatings for photocatalytic applications at the laboratory scale. However, the slow and careful manufacturing and the high temperatures required for the post-deposition treatment make it difficult to scale-up the manufactured goods (Ref 3). As an alternative, thermal spray (TS) can be applied at a faster rate and more cost effectively to achieve photocatalytic $\mathrm{TiO}_{2}$ coatings. Scientific reports based on conventional TS processes have been published, and the use of TS technology has been clearly demonstrated. However, the temperatures involved in the atmospheric plasma spray (APS) or high-velocity-oxygen-fuel spray (HVOF) processes have increased the grain size of the initial feedstock and transformed anatase phase to rutile, which is photocatalytically less active. As a consequence, the effectiveness of the obtained samples is reduced (Ref 4-6).

Alternatively, cold gas spray (CGS) does not require melting of the material to be deposited. Therefore, this technology is able to avoid the undesired phase transformations and growth in the grain size compared with other 
TS processes. A high kinetic nitrogen stream propels powder particles, which are plastically deformed on impact with the substrate. Metallic layers have been built-up due to the ductility of these materials. Nonetheless, ceramic particles cannot be deposited through plastic deformation, and coating a substrate with this feedstock calls for other alternatives. Commonly, CGS $\mathrm{TiO}_{2}$ coatings have been built-up by mechanically anchoring the powder particles onto ductile surfaces of different substrates.

Ballhorn et al. (Ref 7) embedded anatase particles by CGS onto a plastic surface for its application as a photocatalyst. The particles penetrated in the polymer and provided a certain area of the metal oxide on the surface, which was intended to enable the photocatalytic degradation of the contaminants. Later on, Klassen and Kliemann (Ref 8) proposed the manufacturing of metallic objects by means of a photocatalytic coating by CGS, where the starting photocatalytic metal oxide powder was mixed with a ductile metallic powder that provided plastic deformation on particles' impact with the substrate surface. The top surface was covered with $30-80 \%$ of metal oxide particles, which may limit the final performance of the photocatalyst.

Another procedure was proposed by Yamada et al., which ensured that chemical bonding may permit thick $\mathrm{TiO}_{2}$ coatings to be obtained by CGS (Ref 9). Surfaces completely covered by nanostructured anatase particles were obtained with a thickness of more than one hundred micrometers. The particles were not embedded onto the substrate surface; transmission electron microscopy (TEM) revealed that the metal oxide particles were connected as a single crystal. In a further study, the same authors attributed this possibility to a unique chemical route for synthesizing and agglomerating nanostructured anatase crystallites (Ref 10). Nanoporosity of the $\mathrm{TiO}_{2}$ starting powder may lead to the breaking down of the particle when impacting onto the substrates. Then, the crystals are decoupled and newly unstable surfaces bond to other counterparts creating more stable interfaces, which allows for the bonding of the newly impacting particles and thus the building-up of the coating.

In the present study, homogeneous nanostructured anatase coatings have been obtained by CGS starting from a powder with the characteristics of previously mentioned studies (Ref 9, 10). The photocatalytic activity of CGS nano- $\mathrm{TiO}_{2}$ coatings was tested by the degradation of phenol and formic acid in liquid media.

\section{Materials}

\subsection{Coating Preparation and Characterization}

Nanostructured $\mathrm{TiO}_{2}$ powder (T102, TAYCA) based on anatase phase was used as feedstock for developing the CGS photocatalytic active coating. Commercially available $\mathrm{TiO}_{2-x}$ rutile (Metco 102, Sulzer Metco) was sprayed onto steel as support for the catalytic layer using an APS A-3000S system with an F4 plasma torch (Sulzer Metco, Germany). Stainless steel substrates were used for the spray coatings. The CGS equipment was a KINETICS ${ }^{\circledR}$ 4000 (Cold Gas Technology, Germany), with a maximum operating pressure of $40 \mathrm{bar}$, temperature of $800{ }^{\circ} \mathrm{C}$ and nitrogen as the propellant gas. Once spraying conditions were optimized, the coatings were deposited onto stainless steel cylinders $(300 \times 20 \times 10 \mathrm{~mm})$.

Powder and coating cross sections were observed by scanning electron microscopy (Pro-X, Phenom). The grain sizes of the metal oxide powder used in the CGS process were studied by transmission electron microscopy TEM (Hitachi H7100). Crystalline composition of the $\mathrm{TiO}_{2}$ photocatalytic powders was studied by $\mathrm{x}$-ray diffraction (XRD) using a X'Pert PRO MPD diffractometer (PANalytical). Composition of CGS and TS coatings was analyzed by a micro-Raman technique (Labram HR800, Horiba). The hardness of the CGS top coat was measured at load of $500 \mathrm{mN}$ by means of a MXT-a microhardness tester (Matsuzawa) following the UNE 7-423/2 standard.

The dip-coating used for comparative purposes in the photocatalytic tests was based on Evonik P25 ${ }^{\circledR}$ deposited onto a glass cylinder with the same dimensions as the CGS photocatalyst. The immobilization of Evonik ${ }^{\circledR} \mathrm{P} 25 \mathrm{TiO}_{2}$ powder was carried out by dip-coating procedure using a Dip-Coater KSV-DC, KSV Instrument. A glass tube with similar dimensions as the stainless steel cylinder tube was submerged in a suspension made of the catalyst $(4 \mathrm{~g} / \mathrm{L})$ in absolute ethanol for $2 \mathrm{~min}$ with dipping speed of $10 \pm 0.5 \mathrm{~cm} / \mathrm{min}$ and emerged at a withdrawing speed of $50 \pm 0.5 \mathrm{~cm} / \mathrm{min}$. Each step involving dipping/withdrawing is defined as a cycle. The dip-coating cycle was repeated 80 times. Afterward, thermal treatment of the coating at $373 \mathrm{~K}$ for $2 \mathrm{~h}$ was carried out to increase the adhesion of the coating to the glass substrate. The composition of crystalline phases of the $\mathrm{T} 102$ and $\mathrm{P} 25^{\circledR}$ were characterized using XRD (D8 Advance, Bruker). The crystalline size of titania was calculated by means of the Scherrer equation from the broadening of the $\left(\begin{array}{lll}1 & 0 & 1\end{array}\right)$ reflections for anatase and the $\left(\begin{array}{lll}1 & 1 & 0\end{array}\right)$ reflections for the rutile. Roughness was measured using a rugosimeter SJ-210 (Mitutoyo).

\subsection{Photocatalytic Experimental Set-Up}

Photocatalytic experiments were carried out using an annular borosilicate glass photoreactor dimensions of which were external diameter $3.2 \mathrm{~cm}$; and length $30 \mathrm{~cm}$. CGS and dip-coating photocatalysts were placed inside the photoreactor. The reactor volume was $110 \mathrm{~mL}$. The UVA-light source consisted of eight fluorescence tubes, model Philips Cleo $15 \mathrm{~W}$, with a spectral peak centered approximately at $365 \mathrm{~nm}$, located outside the reactor. Starting concentrations of formic acid and phenol were $10 \mathrm{mg} / \mathrm{L}$ in deionized water. The $\mathrm{pH}$ values of the reaction were adjusted to be 3 and 5, respectively. The volume of water treated was $0.3 \mathrm{~L}$, and the inlet flow was $200 \mathrm{~L} / \mathrm{h}$, Fig. 1 shows a sketch of the photocatalytic reactor. Before switching on the UVA light, the catalyst was first exposed to the polluted water stream until dark-adsorption equilibrium was reached. The quantification of pollutants was performed by ion chromatography in the case of formic 
acid. Evolution of phenol concentration was analyzed by liquid chromatography by means of a UV diode array detector. All photocatalytic experiments were performed in triplicate.

\section{Results and Discussion}

\subsection{Coating Development}

Regarding the CGS feedstock (T102), nanostructured particles were agglomerated, obtaining a particle size distribution of $-30+10 \mu \mathrm{m}$ (Fig. 2). The starting nonagglomerated powder was based on pure crystalline anatase as can be observed from the XRD pattern (Fig. 3) with a crystallite size of $11 \mathrm{~nm}$. The XRD pattern of reference $\mathrm{P} 25^{\circledR}$ shows that it is composed of a mixture of anatase and rutile phases (80:20), respectively, with an average crystallite size of $20 \mathrm{~nm}$ for anatase and $25 \mathrm{~nm}$ for rutile. Preliminary trials were carried out by spraying nano-anatase onto smooth stainless steel and ceramic tiles at different spraying conditions ranging from low pressure and temperature values to respective higher values to study the influence of the particle velocity on the deposition behavior. Despite the difference in the operational parameters, the coatings were not built-up for either type of substrates.

Providing roughness to a surface is the usually adopted step for improving the adhesion of the particles in TS processes. Therefore, the substrates were grit-blasted with corundum at 6 bar pressure. Surface roughness values $\left(R_{\mathrm{a}}\right)$ of stainless steel and ceramic tiles were $6.7 \pm 1.9$ and $7.2 \pm 3.2 \mu \mathrm{m}$, respectively. The same spraying conditions as before were used to coat the grit-blasted substrates. Again, stainless steel was not coated in spite of altering the operational conditions of the process. Ceramic tiles were eroded when operating at higher energetic parameters. However, some deposition was observed at low energetic
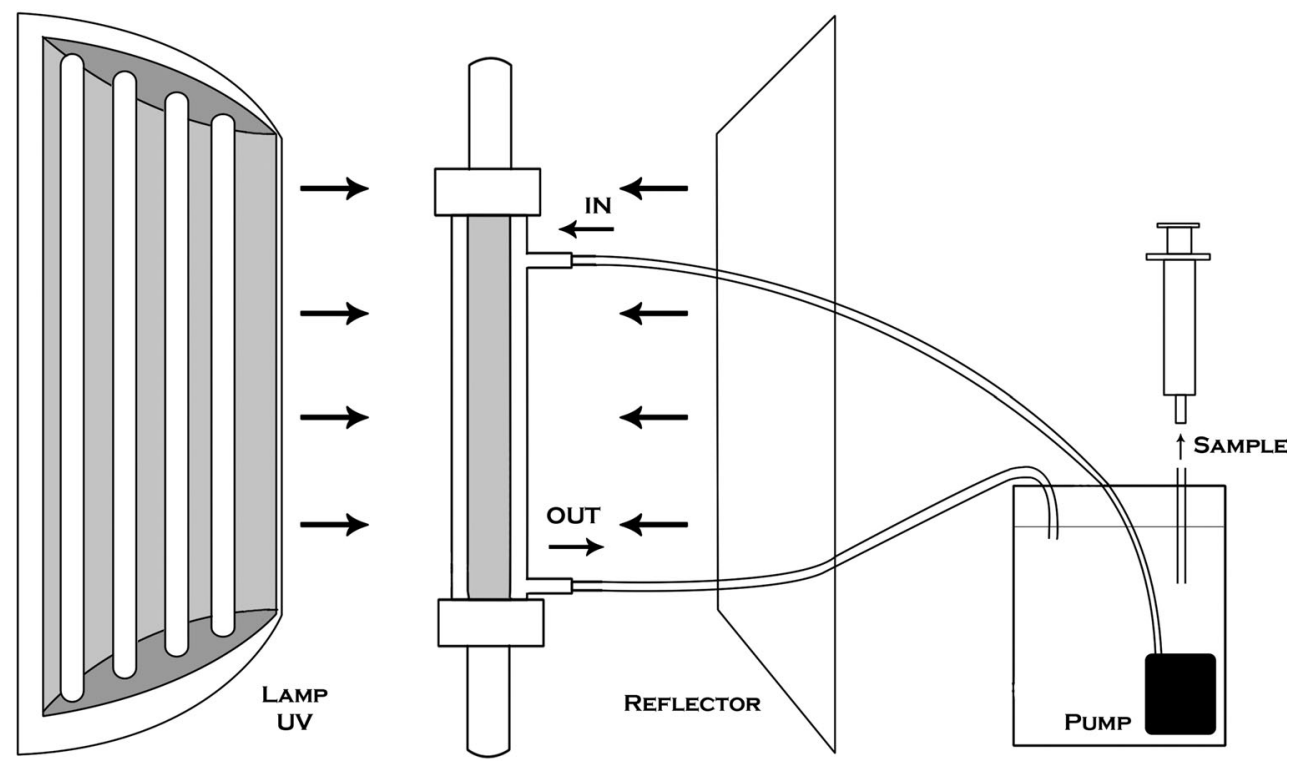

Fig. 1 Sketch of the photocatalytic reactor
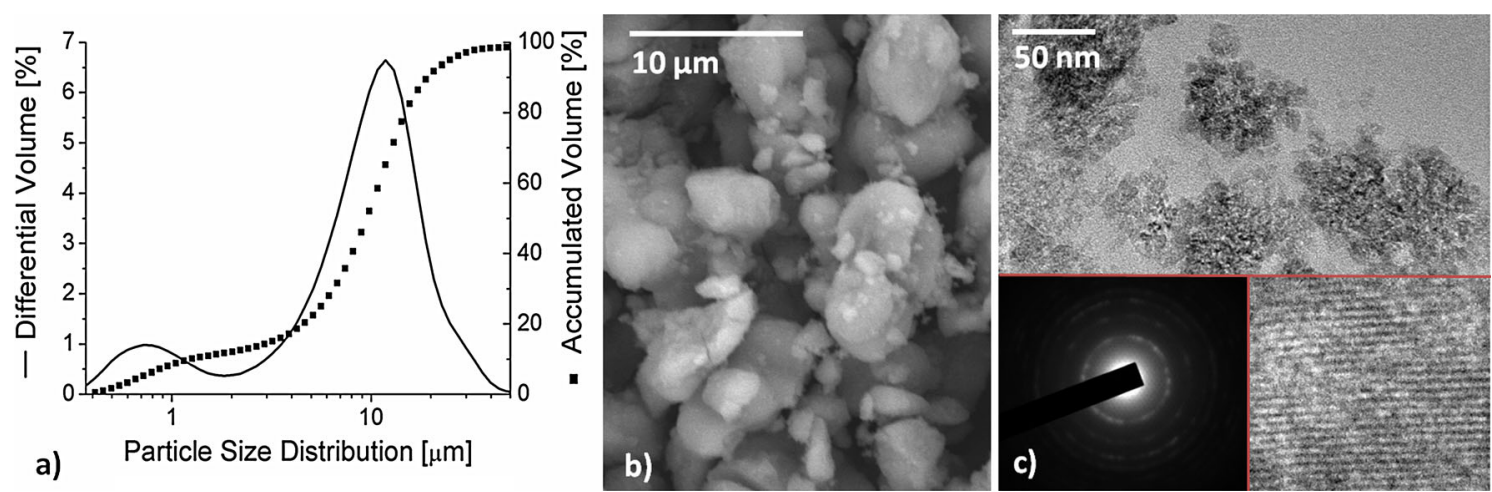

Fig. 2 T102 Feedstock characterization: (a) Particle size distribution, (b) SEM micrograph, and (c) TEM micrograph (crystallographic plane is highlighted) 


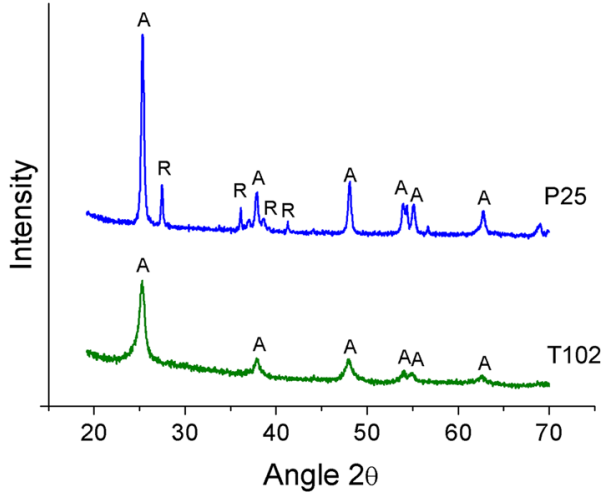

Fig. 3 The XRD spectra of $\mathrm{T} 102 \mathrm{TiO}_{2}$ and $\mathrm{P} 25 \mathrm{TiO}_{2}$ in powder forms (A: anatase, R: Rutile)

spraying conditions, where some of the anatase particles were adhered. Some conclusions from the findings could be drawn: (i) the roughness of the substrate was significant; (ii) substrate composition could be providing chemical affinities during the interaction of the particles after the impact; and (iii) hardness of the substrate may be required for easing this interaction.

CGS coatings are formed due to plastic deformation of the sprayed particles during impact (Ref 11, 12). In this case, agglomerated nano- $\mathrm{TiO}_{2}$ cannot deform plastically, but other mechanisms can occur. Yamada et al. indicated that the breaking down of the particle when impacting onto the substrate may occur, when $\mathrm{TiO}_{2}$ has certain nanoporosity (Ref 9). Besides this, Yang et al. (Ref 13) reported that nanostructured $\mathrm{TiO}_{2}$ particles could deform during impact under certain operational conditions. Moreover, chemical bonding between particles and substrate or among particles may indicate that the substrate would play a key role in terms of hardness and chemical composition when nanostructured anatase particles are adhered by CGS. Therefore, it was decided to coat stainless steel with titanium sub-oxide $\left(\mathrm{TiO}_{2-x}\right)$ by means of APS as bond coat. The composition of this bond coat was based on reduced stoichiometries of titanium dioxide; corresponding spraying conditions were reported in previous surveys (Ref 14,15$)$. This new coated surface allows for the breakdown/deformation of nano- $\mathrm{TiO}_{2}$ particles, and its composition may facilitate the formation of chemical bonds and increase the coating adhesion. Moreover, the top surface of an APS metal oxide coating presents a characteristic roughness $(9.5 \pm 3.1 \mu \mathrm{m})$, which was observed to be a key factor during the initial trials. The spray conditions were adjusted to have sufficient particle velocity for activating the bonding mechanisms, but not so high to cause the erosion of the APS $\mathrm{TiO}_{2-x}$ coating.

Figure 4 shows the cross-sectional area of a multilayered sample with a nanostructured anatase coating deposited onto APS $\mathrm{TiO}_{2-x}$ layer. Detailed observation of the interface between both coatings shows that no delamination was found, and good adhesion was obtained (Fig. 5). Raman spectroscopy shown in Fig. 6 confirmed that the top surface of the CGS coating was based on

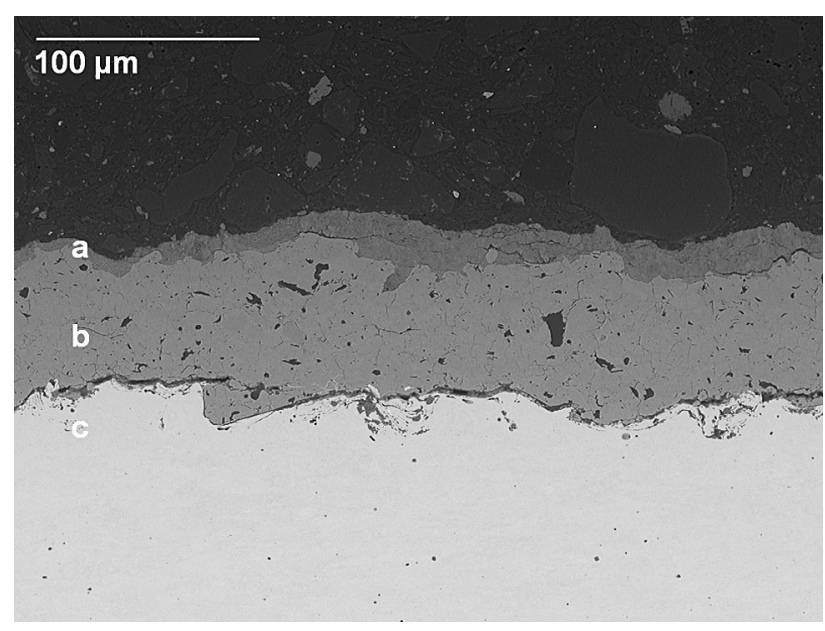

Fig. 4 SEM micrograph of the CGS coating cross-sectional area: (a) CGS nano-TiO ${ }_{2}$ layer, (b) APS $\mathrm{TiO}_{2-}$ coating, and (c) steel

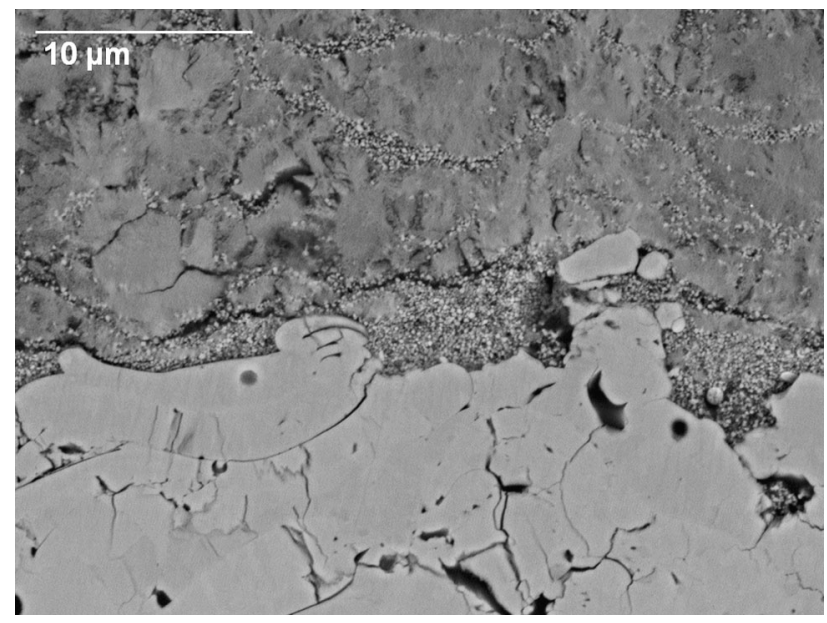

Fig. 5 Interface between the APS $\mathrm{TiO}_{2-x}$ bond coat and CGS nano- $\mathrm{TiO}_{2}$ photoactive top coat

anatase phase, which is required to accomplish the photocatalytic process. Besides this, nanotextures present on the top surface of the CGS coating can be observed in Fig. 7.

In order to explain the building-up of the coating, the following mechanism is described. The microtexture of the APS bond coat produced a profile that favored the anchoring of nanostructured CGS coating. Energy released during cold spraying could be sufficient to create chemical bonds between the particles and substrate. Then, nano- $\mathrm{TiO}_{2}$ particles were bonded, and the thickness of the coating increased. Although roughness may not be found for easing the adhesion regarding coarser anatase particles that arrived on the substrate after the finest ones were deposited, their affinity could be just enough for creating the required linkage. Figure 8 represents the each step of the possible mechanism. 


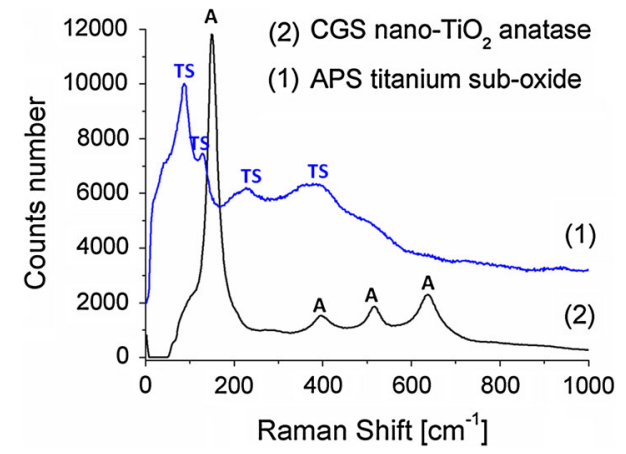

Fig. 6 Raman spectra of APS titanium sub-oxide coating (Ref 16) and CGS nanostructured anatase coating (Ref 17). A: Anatase, TS: Titanium Sub-oxide

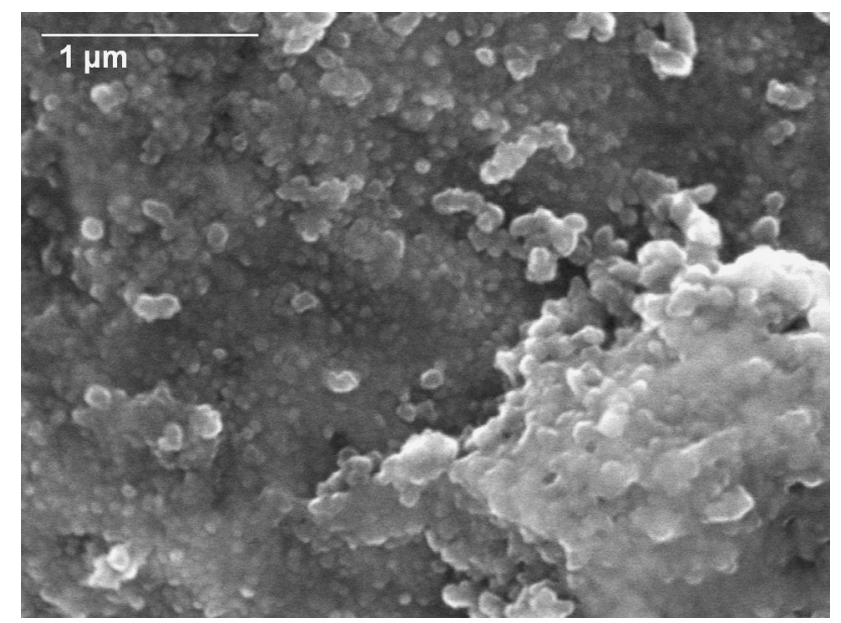

Fig. 7 FESEM micrograph of the CGS nano-TiO2 coating surface

Microhardness of the nanostructured anatase layer has a mean value of $132 \pm 32 \mathrm{HV}$, which is much lower than that of bulk $\mathrm{TiO}_{2}$. Spraying process has developed necks among the particles, but the overall structure is not as consistent as the bulk titanium dioxide (in agreement with other authors' findings (Ref 18)).

\subsection{Photocatalytic Performance}

Formic acid and phenol were selected as pollutants in aqueous phase due to their different degradation mechanisms. The photocatalytic degradations of these pollutants in the presence of the coatings are shown in Fig. 9 and 10, respectively. The photocatalytic degradation of formic acid follows a single-stage oxidation mechanism (yielding $\mathrm{CO}_{2}$ and $\mathrm{H}_{2} \mathrm{O}$ ). Formic acid is oxidized mainly via electron transfer to $\mathrm{TiO}_{2}$ (Ref 19). However, phenol is degraded mainly by $\mathrm{H}$-abstraction by hydroxyl radicals (yielding oxidation intermediates) (Ref 20).

CGS nano- $\mathrm{TiO}_{2}$ successfully degraded formic acid; no significant differences were observed compared to P25 ${ }^{\circledR}$ coating. On the other hand, $\mathrm{P} 25^{\circledR}$ coating had slightly improved efficiency compared to CGS nano- $\mathrm{TiO}_{2}$ on the
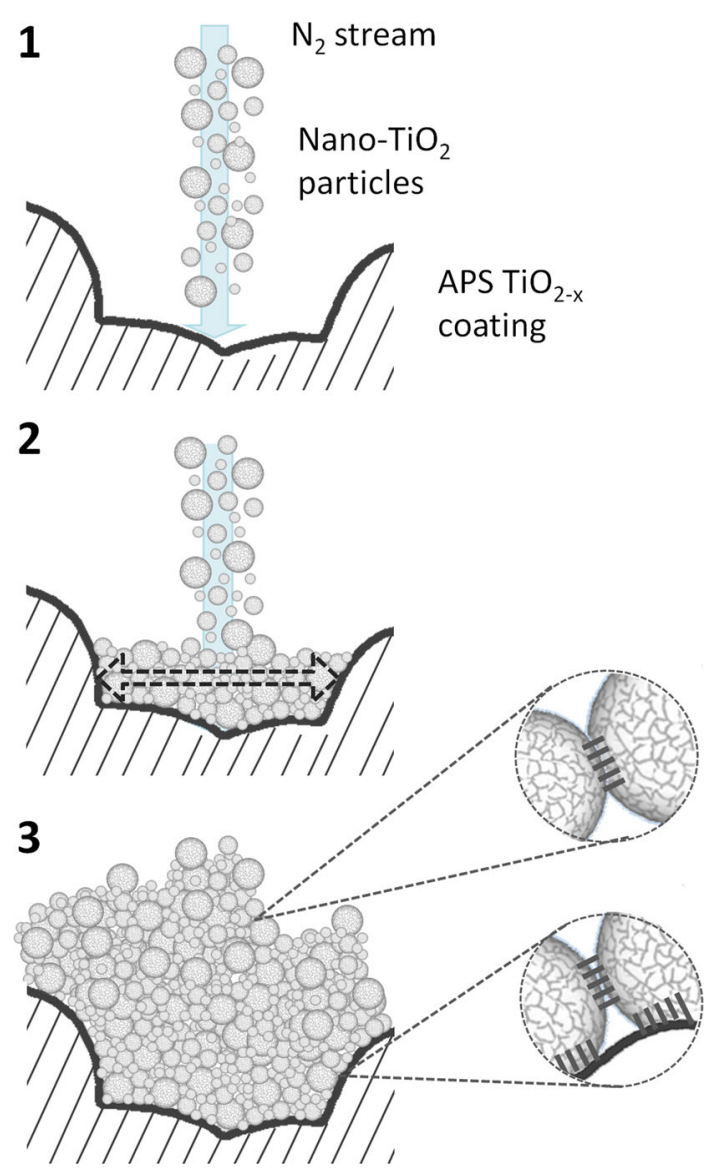

Fig. 8 Possible mechanism of bonding between CGS nano- $\mathrm{TiO}_{2}$ particles and APS $\mathrm{TiO}_{2-x}$ bond coat

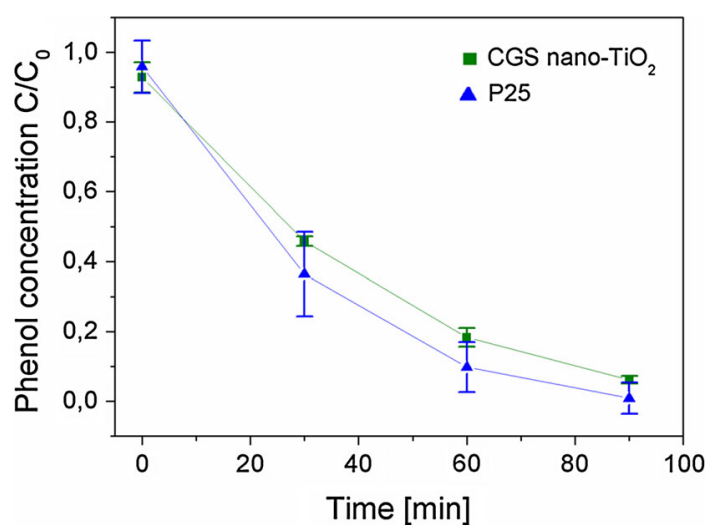

Fig. 9 Photodegradation of phenol in aqueous phase

removal of phenol from water. Phenol-type molecules are degraded mainly via hydroxyl radicals. Previous investigations have demonstrated that the formation rate of $\cdot \mathrm{OH}$ on the surface of irradiated commercial $\mathrm{P} 25^{\circledR}$ was much higher than anatase particle with lower particle size (Ref 21, 22). Furthermore, the presence of a $20 \%$ of rutile phase in $\mathrm{P}_{2} 5^{\circledR} \mathrm{TiO}_{2}$ can have certain synergetic effect in the production of hydroxyl radicals (Ref 23). 


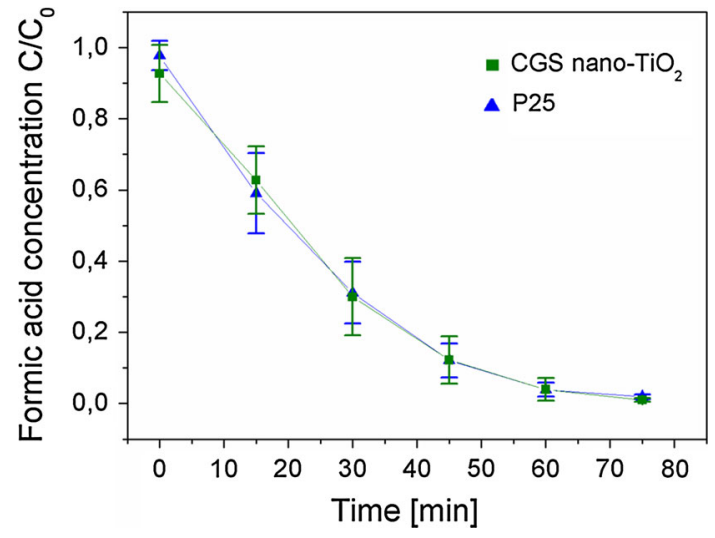

Fig. 10 Photodegradation of formic acid in aqueous phase

It is worth mentioning that only $5 \mathrm{~min}$ were required for coating a cylinder with a length and diameter of 30 and $2 \mathrm{~cm}$, respectively, using cold spray equipment. On the other hand, an overall time above 240 minutes was consumed when depositing the $\mathrm{P} 25^{\circledR}$ coating by means of dip-coating method. Therefore, CGS competitiveness in nano- $\mathrm{TiO}_{2}$ photocatalysts is not just based on their operational times needed for manufacturing the coatings, but also on the fact that the photoefficiency of this coating on the removal of pollutants from water is comparable to the one obtained when using commonly available standard $\mathrm{P} 25^{\circledR}$ coatings. Besides this, lower layer based on titanium sub-oxide might not only be favoring the deposition of CGS nano- $\mathrm{TiO}_{2}$ particles, but could be also acting as a current collector due to its low electric resistivity $(0.33 \Omega / \mathrm{cm}(\operatorname{Ref} 14)$.

In this way, new strategies in the fabrication of nanostructured ceramic coatings by means of CGS technology must take into account substrate hardness, roughness, and composition with the purpose of developing respectively the breaking down, entrapping, and chemical bonding between the particles and the substrate.

\section{Conclusions}

CGS nano-anatase coatings were deposited onto steel cylinders previously coated with titanium sub-oxide layers obtained by atmospheric plasma spray. The photocatalytic coating preserved its composition and nanostructure of the feedstock powder. Titanium sub-oxide coating provided a necessary surface geometry and composition that favored the deposition of anatase particles, which were not plastically deformed at the impact, but bonded by chemical interactions with the substrate; hard, rough substrate surface may ease the breakdown of agglomerated nanostructured particles and their anchorage. Phenol and formic acid in aqueous phase were degraded, and the results were compared to those obtained using P $25^{\circledR}$ layers obtained by dip-coating. The photocatalytic efficiency of CGS nano- $\mathrm{TiO}_{2}$ coatings was comparable to the one obtained with $\mathrm{P} 25^{\circledR}$ for the removal of low concentrations of pollutants from water.

\section{Acknowledgments}

The authors wish to thank the Generalitat de Catalunya for the financial support for this research through project 2009 SGR 00390; as well as the Spanish Ministry of Science and Innovation for their financial support through the projects CTQ2008-05961-C02-02 and IPT-2011-1113310000.

\section{References}

1. A. Fujishima and X. Zhang, Titanium Dioxide Photocatalysis: Present Situation and Future Approaches, C. R. Chim., 2006, 9(5-6), p 750-760

2. L.A. Dobrzanski, M. Pawlyta, and A. Hudescki, Conceptual Study on a New Generation of the High-Innovative Advanced Porous and Composite Nanostructural Functional Materials with Nanofibers, J. Achiev. Mater. Manuf. Eng., 2011, 49(2), p 550

3. M. Gardon and J.M. Guilemany, A Review on Fabrication, Sensing Mechanisms and performance of Metal Oxide Gas Sensors, J. Mater. Sci. Mater. Electron., 2013, 24(5), p 1410-1421

4. N. Berger-Keller, G. Bertrand, C. Filiatre, C. Meunier, and C. Coddet, Microstructure of Plasma-Sprayed Titania Coatings Deposited from Spraydried Powder, Surf. Coat. Technol., 2003, 168, p 281-290

5. F.L. Toma, G. Bertrand, S. Begin, C. Meunier, O. Barres, D. Klein, and C. Coddet, Microstructure and Environmental Functionalities of $\mathrm{TiO}_{2}$-Supported Photocatalysts Obtained by Suspension Plasma Spraying, Appl. Catal. B, 2006, 68, p 74-84

6. F.-L. Toma, G. Bertrand, S.O. Chwa, C. Meunier, D. Klein, and C. Coddet, Comparative Study on the Photocatalytic Decomposition of Nitrogen Oxides Using $\mathrm{TiO}_{2}$ Coatings Prepared by Conventional Plasma Spraying and Suspension Plasma Spraying, Surf. Coat. Technol., 2006, 200, p 5855-5862

7. R. Ballhorn, F. Peterka, H. Kreye, I. Burlacov, T. Stoltenhoff, and J. Jirkovsky, Production of Photocatalytically Active Polymer Surfaces of Variable Composition Comprises Cold Gas Spraying them with Oxide Powder to Produce Adherent Photocatalytic Layer, German Patent Number: DE102004038795A1, 2004

8. T. Klassen and J.A. Kliemann, Method for manufacturing a photocatalytically active layer, United States Patent US2007148363A1, 2007

9. M. Yamada, H. Isago, K. Shima, H. Nakano, and M. Fukumoto, Deposition of $\mathrm{TiO}_{2}$ Ceramic Particles on Cold Spray Process, Thermal Spray: Global Solutions for Future Applications, B.R. Marple, A. Agarwal, M.M. Hyland, Y.-C. Lau, C.-J. Li, R.S. Lima, and G. Montavon, Eds., Singapore, 2010

10. N. TjitraSalim, M. Yamada, H. Nakano, K. Shima, and M. Fukumoto, The Synthesis of Titanium Dioxide Powders for Cold Spray, Thermal Spray 2011: Proc. International Thermal Spray Conf., B.R. Marple, A. Agarwal, M.M. Hyland, Y.-C. Lau, C.-J. Li, R.S. Lima, and A. McDonald, Eds., September 27-29, 2011, (Hamburg)

11. V. Champagne, The Cold Spray Materials Deposition Process: Fundamentals and Applications, Woodhead Publishing in Materials, Cambridge, 2007. ISBN-10: 1420066706

12. A. Papyrin, Cold Spray Technology, Elsevier Publications, Amsterdam, 2007. ISBN-10: 0080451551

13. G.J. Yang, C.J. Li, F. Han, W.Y. Li, and A. Ohmori, Low Temperature Deposition and Characterization of $\mathrm{TiO}_{2}$ Photocatalytic Film Through Cold Spray, Appl. Surf. Sci., 2008, 254, p 3979-3982

14. M. Gardon and J.M. Guilemany, The Influence of Titanium Suboxides in Thermal Sprayed Coatings, Thermal Spray 2012: Proc. International Thermal Spray Conference, B.R. Marple, A. Agarwal, L. Filofteia-Toma, M.M. Hyland, Y.-C. Lau, C.-J. Li, R.S. Lima, and A. McDonald, Eds., May 21-24, 2012, (Houston)

15. M. Gardon, S. Dosta, J.M. Guilemany, M. Kourasi, B. Mellor, and R. Wills, Improved, High Conductivity Titanium Sub-oxide 
Coated Electrodes Obtained by Atmospheric Plasma Spray, $J$. Power Sour., 2013, 238, p 430-434

16. A. Skopp, N. Kelling, M. Woydt, and L.-M. Berger, Thermally Sprayed Titanium Suboxide Coatings for Piston Ring/Cylinder Liners Under Mixed Lubrication and Dry-Running Conditions, Wear, 2007, 262, p 1061-1070

17. H. Cheng, J. Ma, Z. Zhao, and L. Qi, Hydrothermal Preparation of Uniform Nanosize Rutile and Anatase Particles, Chem. Mater., 1995, 7, p 663-671

18. S.-Q. Fan, G.-J. Yang, C.-J. Li, G.-J. Liu, C.-X. Li, and L.-Z. Zhang, Characterization of Microstructure of $\mathrm{Nano}^{-\mathrm{TiO}_{2}}$ Coating Deposited by Vacuum Cold Spraying, J. Therm. Spray Technol., 2006, 15(4), p 513

19. L. Davydov and P.G. Smirniotis, Quantification of the Primary Processes in Aqueous Heterogeneous Photocatalysis Using Single-Stage Oxidation Reactions, J. Catal., 2000, 191, p 105-115
20. E. Grabowska, J. Reszczyńska, and A. Zaleska, Mechanism of Phenol Photodegradation in the Presence Of Pure and Modified$\mathrm{TiO}_{2}$ : A Review, Water Res., 2012, 46(17), p 5453-5471

21. C. Fernández-Rodríguez, J.M. Doña-Rodríguez, O. GonzálezDíaz, I. Seck, D. Zerbani, D. Portillo, and J. Perez-Peña, Synthesis of Highly Photoactive $\mathrm{TiO}_{2}$ and $\mathrm{Pt} / \mathrm{TiO}_{2}$ Nanocatalysts for Substrate-Specific Photocatalytic Applications, Appl. Catal. B, 2012, 125, p 383-389

22. A.G. Agrios and P. Pichat, Recombination Rate of Photogenerated Charges Versus Surface Area: Opposing Effects of $\mathrm{TiO}_{2}$ Sintering Temperature on Photocatalytic Removal Of Phenol, Anisole, and Pyridine in Water, J. Photochem. Photobiol. A, 2006, 180, p 130-135

23. B. Tryba, M. Toyoda, A.W. Morawski, R. Nonaka, and M. Inagaki, Photocatalytic Activity and $\mathrm{OH}$ Radical Formation on $\mathrm{TiO}_{2}$ in the Relation to Crystallinity, Appl. Catal. B, 2007, 71, p 163-168 